\title{
O encolhimento dos exércitos
}

\author{
Manuel Domingos Neto e Luís Gustavo Guerreiro
}

As estatísticas indicam
uma tendência mundial
de redução dos efetivos
militares. O fenômeno
é liderado pelos países
mais ricos. Os autores
revelam que não se
trata de abrandamento

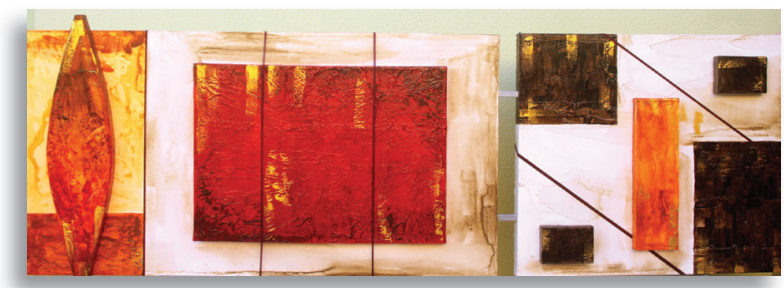

de suas capacidades

militares, mas de uma crescente

substituição de combatentes por

equipamentos altamente sofisticados

e consideravelmente mais letais.

Palavras-chave: Exército, Militar, Política de Defesa, Segurança Internacional.

\section{The shrinking of the armies}

Statistics indicate global trend of reduction of military forces. The phenomenon is led by the richest countries. The authors show that this is not about slowing down their military capabilities, but in increasing replacement of combatants by highly sophisticated and considerably more lethal equipment.

Key words: Army, Military, Defense Policy, International Security.

Manuel Domingos Neto:

Professor do Instituto de Estudos

Estratégicos da Universidade

Federal Fluminense e coordenador do Observatório das Nacionalidades.

Luís Gustavo Guerreiro:

Mestre em Sociologia, indigenista

da FUNAI e pesquisador do

Observatório das Nacionalidades. 


\section{INTRODUÇÃO}

Os dados disponíveis sobre o conjunto de efetivos militares no mundo são pouco confiáveis e mesmo contraditórios; não são organizados segundo critérios universais nem primam pelo rigor conceitual; podem semear mais confusão do que propiciar esclarecimentos.

Segundo o Departamento de Estado do governo norte-americano, entre 1995 e 2005, o número total de efetivos nas forças armadas do mundo teria caído de 22,8 para 19,2 milhões de homens, o que representaria uma redução de $16 \% .^{1}$ Diante do crescimento da população mundial, a redução seria ainda mais acentuada, girando em torno de $26 \%$. Para esta fonte, o total dos efetivos equivaleria a 0,40\% ou 0,30\% da população global.

De acordo, porém, com o Banco Mundial, os efetivos teriam aumentado em 6,5 milhões de homens entre 1985 e 2006. ${ }^{2}$ Por sua vez, o International Institute for Strategic Studies (IISS), sediado em Londres e afinado com os objetivos estratégicos do Reino Unido e de seu padrinhoparceiro, os Estados Unidos, estima que entre 1985 e 2000, os efetivos militares mundiais cresceram aproximadamente 35\%, confirmando a tendência apontada pelo Banco Mundial. ${ }^{3}$ Mas a credibilidade desta instituição londrina é cada vez mais arranhada por sua defesa obstinada das agressões levadas a cabo pela OTAN.

Operando com séries estatísticas mais amplas e metodologias mais rebuscadas, o Stockholm International Peace Research Institute (SIPRI), financiado pelo governo sueco - mas apresentando-se como instituição independente, inclusive, mantendo escritórios em Washington e Pequim - revela dados concernentes às 15 potências com os maiores gastos em Defesa que permitem concluir que, entre 1985 e 2003, houve uma inequívoca queda dos efetivos militares, em números absolutos e relativos. Estas potências seriam os Estados Unidos, China, França, Reino Unido, Rússia, Japão, Alemanha, Arábia Saudita, Índia, Itália, Brasil, Coreia do Sul, Canadá, Austrália e Espanha. ${ }^{4}$

1 Fonte: Sítio do Departamento de Estado dos EUA. Disponível em: http://www.state.gov/t/ avc/rls/rpt/wmeat/2005/180135.htm. Acesso em: 8/1/2011.

2 Fonte: Banco Mundial. Disponível em: http://data.worldbank.org/indicator/MS.MIL.TOTL. P1/countries/1W?display=default. Acesso em: 8/1/2011.

3 IISS (International Institute for Strategic Studies). The Military Balance 2001-2002. Oxford: Oxford University Press, 2001.

4 Além das fontes mencionadas, todas relevantes para o estudo dos efetivos militares, estão, obviamente, os relatórios dos ministérios da Defesa, os documentos parlamentares e os informes dos comandos militares dos diversos países. Neste trabalho, entretanto, usamos incidentalmente estas fontes. 
Tais potências, por suas capacidades próprias, são as mais influentes quanto à disseminação de conceitos estratégicos, esquemas operacionais e modelos de organizações militares. Estados Unidos, China, Japão, Alemanha, França, Índia, Grã-Bretanha e Rússia detêm dois terços da atividade econômica do mundo (PIB) e 51\% da população; lideram a corrida espacial, dispõem de quase todo o armamento nuclear existente bem como da indústria bélica mundial. Assim, controlam o comércio internacional de equipamentos militares e as decisões dos grandes fóruns internacionais, definindo tanto a dita "ordem mundial" quanto as tendências das políticas de defesa. O gráfico a seguir (GRÁFICO 1) revela a nítida propensão de encolhimento de seus efetivos militares.

\section{Gráfico 1: População e efetivos militares nas 15 maiores potências}

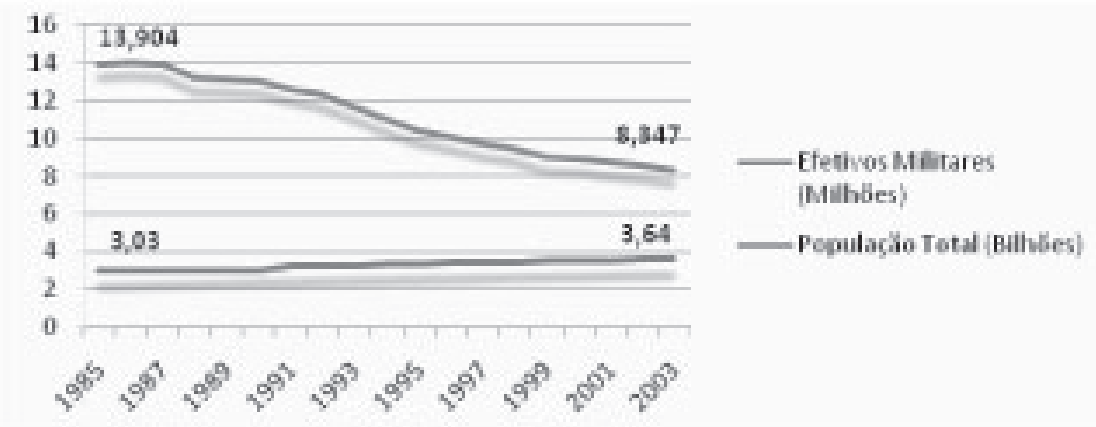

Fonte: Gráfico elaborado a partir de dados coletados no SIPRI, no endereço: http://first.sipri. org/search? country=AUS\&dataset=armed-forces. ${ }^{5}$ Acesso em: 22/8/2011.

No tocante a poderio militar, as "evidências estatísticas" precisam ser tratadas com prudência; os quantitativos revelados, notadamente as informações apresentadas como "oficiais", refletem orientações politicas e interesses tático-estratégicos. Dados relevantes para os assuntos militares sempre serão, antes de tudo, indutores de opinião, não de avaliação isenta, se é que isso existe, tratando-se de estudos políticos.

Com frequência, observadores menos atentos são facilmente levados a desvios de entendimento, a começar pelo significado da expressão "efetivo militar". Corporações e organizações armadas e com capacidade de combate podem ser excluídas, por exemplo, do rol dos

5 Os efetivos considerados são o pessoal em serviço militar ativo, incluindo as forças paramilitares envolvidas na formação, organização, equipamento e controle que estejam aptos para apoiar ou substituir as forças militares regulares. 
efetivos. Em alguns destes países, sobretudo na África e na América Latina, nem sempre há clara distinção entre efetivo militar e efetivo policial. Um país como o Brasil, apesar de seu desenvolvimento econômico e sua estabilidade institucional, ainda dispõe de um aparato policial militarizado e muitos comandantes militares aceitam de bom grado assumir funções policiais. Atualmente, contingentes militares são empregados na repressão policial no Rio de Janeiro. Em países africanos em processo de destribalização, onde os conflitos étnicos são permanentes, muitas vezes há pouca distinção entre forças armadas e milícias tribais.

Empresas de mercenários, cada vez mais presentes nos conflitos, nem sempre são contabilizadas. Estimativas sobre organizações paramilitares com notável capacidade operacional são costumeiramente fantasiosas. Acrescente-se ainda o fato de que as fontes mais empregadas nas análises sobre assuntos militares são ocidentais. Alguns dados não passam de especulações grosseiras, como as relativas à ex-União Soviética ao longo da Guerra Fria e, atualmente, a certos países árabes, o Iran e a Coreia do Norte.

Além disso, as pesquisas geradoras de estatísticas não são padronizados. Os dados referentes aos gastos militares são particularmente nebulosos. Por exemplo, pensões, aposentadorias e investimentos em C\&T podem ou não estar incluídos nos orçamentos de defesa. Em regra, os diferentes institutos de pesquisa ou órgãos oficiais se especializam em coletar ou priorizar determinados tipos de informação, como os investimentos em C\&T, embargos multilaterais na produção de armas e comércio de material de guerra. Mas é impossível contabilizar o contrabando de armas. Finalmente, ressalte-se que, na maioria das vezes, os recortes temporais variam de pesquisa para pesquisa.

Neste trabalho, nos apoiamos, sobretudo, nos dados do SIPRI, eventualmente complementados com informações de outras fontes. Comentamos a princípio certos aspectos da tendência geral de redução dos efetivos militares dos Estados nacionais e tecemos considerações sobre suas possíveis repercussões políticas destacando aquilo que, em nosso ponto de vista, é mais relevante: a fragilização da legitimidade da força militar. Pelo menos nos últimos dois séculos esta legitimação foi calcada em discursos de defesa dos "interesses nacionais"; hoje é dirimida em noções nada precisas, como a "responsabilidade de proteger", aceita pela ONU. 


\section{A REDUÇÃO DOS CONTINGENTES}

O exemplo mais visível da tendência de redução do tamanho dos Exércitos vem seguramente da China. Entre 1985 e 2003, o efetivo chinês aumentou de 4.100.000 para 2.241.000 homens. Em termos absolutos e relativos, foi um drástico encolhimento exatamente no momento em que esse país passou a se projetar como potência econômica e a mostrar-se disposto a ocupar espaço ampliado no jogo político internacional. No mesmo período, os efetivos russos foram reduzidos de 2.600 .000 para 863 mil e os estadunidenses de 2.244 .000 para $1.496 .000 .{ }^{6}$ Neste período, estas duas potências não deixaram de guerrear.

Observe-se que os três países viviam quadros econômicos e perspectivas políticas bem distintas. Enquanto os Estados Unidos pretendiam alçar-se à condição de definidor solitário da ordem mundial, a China desenvolvia uma agressiva política de exportações de bens industriais, garantia a proteção de seu entorno estratégico e investia seriamente dos domínios espacial e cibernético. Por sua vez, a Rússia, detentora de tecnologia militar avançada, buscava sua reconstrução política e econômica após o colapso da União Soviética. O gráfico a seguir (GRÁFICO 2) revela que a China respondeu pela redução mais notável em curtíssimo período de tempo:

\section{Gráfico 2: Efetivos militares (EUA, Rússia e China)}

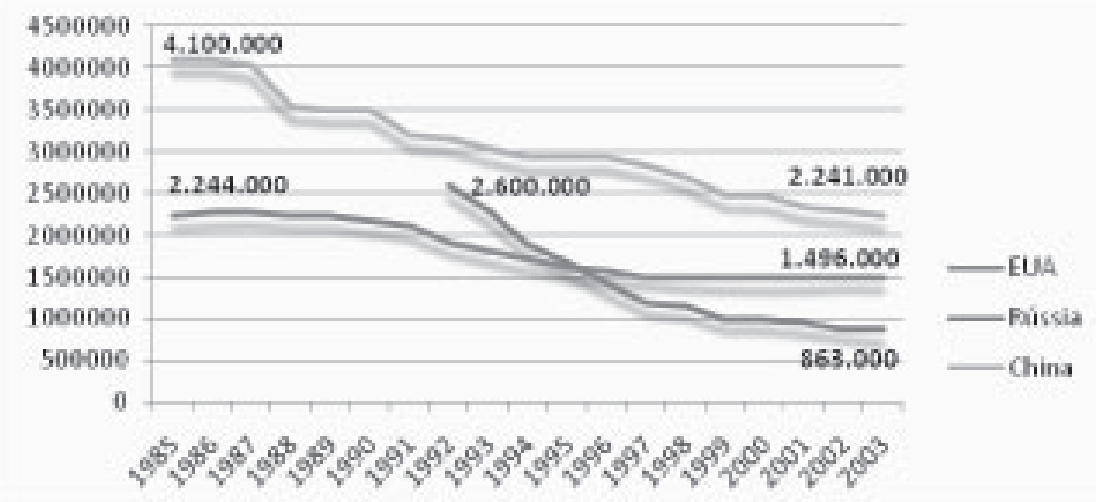

Fonte: Gráfico elaborado a partir dos dados obtidos no SIPRI. No endereço http://first sipri. org/search? Acesso em: 10/8/2011.

6 O SIPRI afirma não possuir os dados relativos aos efetivos militares da Rússia antes de 1992 em virtude da Guerra Fria e da dificuldade de acesso a "informações seguras". 
As potências europeias também apresentaram significativa redução de seus efetivos, apesar de estarem envolvidas em operações relevantes no Iraque e no Afeganistão e, atormentadas por suas carências em energia, se prepararem para intervenções em países produtores de petróleo no norte da África. França, Reino Unido, Alemanha e Itália reduziram seus efetivos em 207 mil, 179 mil, 210 mil e 120 mil indivíduos, respectivamente, no período em discussão (GRÁfICO 3).

No Reino Unido, os cortes de pessoal se mostram tão drásticos que podem deixar seu Exército com o menor contingente desde a Guerra dos Bôeres, há mais de cem anos. Na Europa, em geral, o encolhimento verificou-se antes dos sinais da crise econômica desencadeada a partir de 2008, que obrigou a pesados cortes orçamentários, não poupando os investimentos em Defesa. O caso europeu serve igualmente para demonstrar que a redução de contingentes militares ocorre sem conexões mecânicas com os descaminhos da economia. Em outras palavras, as dificuldades orçamentárias dos Estados não são necessariamente a principal causa da redução dos efetivos. Ademais, tal redução pode significar reforço de capacidade militar, não o contrário.

\section{Gráfico 3: Efetivos militares na Europa (França, Reino Unido, Alemanha e Itália)}

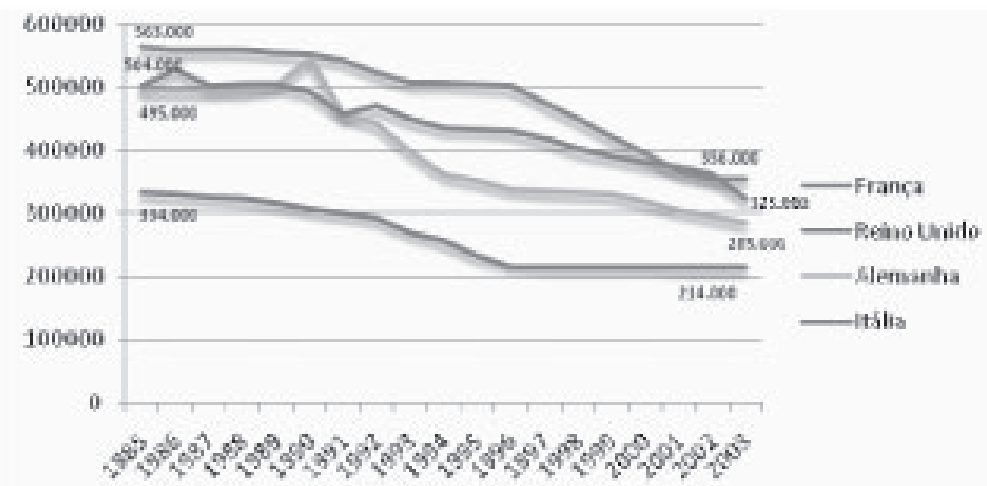

Fonte: Gráfico elaborado a partir dos dados obtidos no SIPRI. No endereço http://first.sipri.org/search? Acesso em: 10/8/2011.

A redução de efetivos também ocorre, de forma mais moderada, em países que, embora não integrem o bloco hegemônico, detêm grandes contingentes como Índia, Coreia do Sul e Turquia. A Índia diminuiu seu 
contingente de 1.260 .000 para 1.205 .000 entre 1985 e 2003, enquanto a Coreia do Sul passava de 600 mil em 1985 para 750 mil em 1994, recuando para 587 mil em 2003. A Turquia, que contava com um efetivo de 879 mil em 1987, o reduziu para 823 mil em 2003. ${ }^{7}$

Sendo inequívoca a tendência de encolhimento das forças armadas nas principais potências, como entender a conclusão do Banco Mundial de que os efetivos militares teriam aumentado em 6,5 milhões entre 1985 e 2006?

A elevação registrou-se em países em desenvolvimento ou pouco desenvolvidos, notadamente naqueles mais atormentados por conflitos internos, tensões de fronteira ou ameaças de agressão de grandes potências.

$\mathrm{Na}$ verdade, essas três possibilidades se combinam, porquanto a maioria dos conflitos internos em países não industrializados - mas detentores de recursos naturais ou de posições geoestratégicas relevantes - tem como causa ingerências externas. Através da OTAN, os Estados Unidos, França, Alemanha e Reino Unido se empenham sistematicamente na desestabilização dos governantes norte-africanos e do Oriente Médio. A França se destaca por sua agressiva intervenção na porção subsaariana enquanto a China vai estabelecendo de forma diferenciada sua presença em todo o continente africano. Tensões fronteiriças, disputas religiosas, conflitos étnicos, regimes autocráticos e ditaduras militares embutem frequentemente lances estratégicos dos que disputam o mando global. Estas interferências podem ser diretas e explícitas ou mascaradas por obstáculos ao estabelecimento de acordos de paz. A instabilidade em países não desenvolvidos, seus confrontos domésticos sangrentos e seus conflitos externos alimentam a lucrativa indústria bélica situada nas grandes potências, que representa milhões de empregos diretos e indiretos e impulsiona o desenvolvimento tecnológico dos setores industrial e de serviços como um todo.

O SIPRI, que há 22 anos coleta dados sobre a produção de armamentos, elabora anualmente uma lista das 100 maiores empresas produtoras de armas. Em 2008, em plena eclosão da crise econômico-financeira, a pesquisa confirmou a tendência de crescimento no comércio mundial de armas, com um acréscimo de 39 bilhões de dólares em comparação a 2007. Neste domínio, a concentração é impressionante: o peso das cinco maiores empresas de armas de alta tecnologia no total das vendas mundiais subiu de $22 \%$ em 1990 para 43\% em 2005, deixando claro o poderio

7 Fonte: SIPRI. Disponível em http://first.sipri.org/search? Acesso em: 8/8/2011. 
de poucas corporações no referente à produção e ao fornecimento de material de guerra. O gráfico a seguir (GRÁFICO 4) identifica a posição das dez maiores empresas bem como seus países de origem:

\section{Gráfico 4: Volume de vendas das 10 maiores empresas de armamento (em US\$ bilhões)}

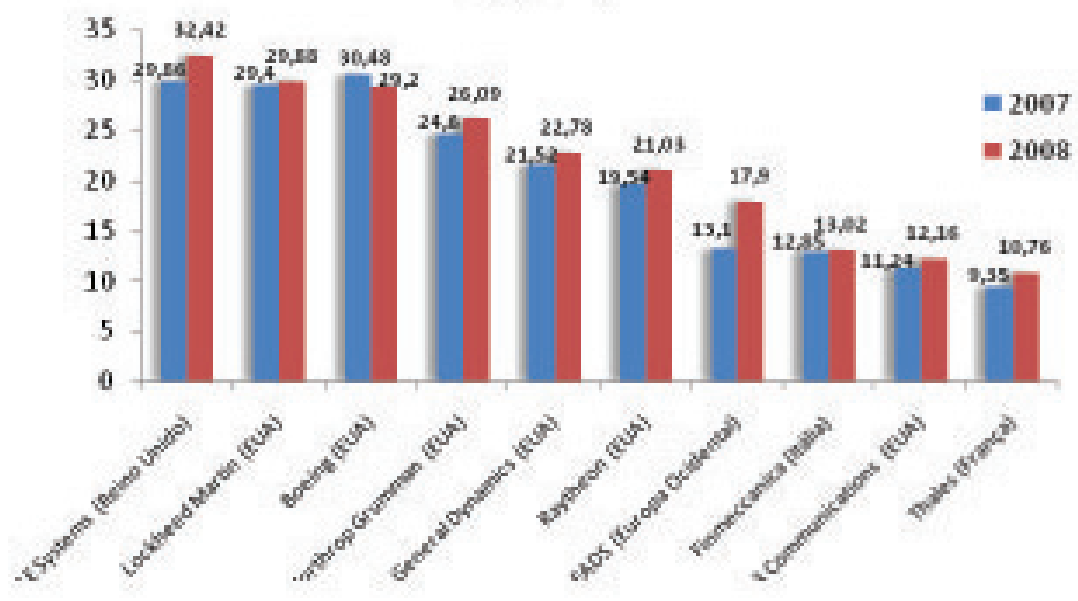

Fonte: Gráfico elaborado a partir de dados do documento The SIPRI top 100 arms-producing companies, 2008. Disponível em: http://books.sipri.org/files/FS/SIPRIFS1004.pdf. Acesso em: $11 / 6 / 2010$.

Quem pesquisa, inova e produz, quer vender. E os principais candidatos a clientes da indústria bélica - hoje eufemisticamente dita "indústria de defesa" - sendo beligerantes em potencial, são estimulados - quando não constrangidos - a guerrear.

Conviria assinalar o crescente interesse de empresas civis neste ramo industrial. Variadas empresas voltadas para o consumo "não militar" são cada vez mais solicitadas a produzir sistemas de armas e equipamentos de alta tecnologia. Trata-se de uma mudança qualitativa no sistema tradicional de produção de armamentos com profundos impactos na composição do pessoal empregado nas forças armadas. Cresce o número de cientistas e trabalhadores civis em atuação no setor de defesa. Antes, o spin-off da tecnologia militar para o setor civil era um importante mecanismo para agregar valor à indústria militar; a tendência crescente hoje é o spinning-in, ou seja, a transferência de tecnologia civil para os militares. Assim, o desempenho de empresas civis especializadas não pode ser descartado da discussão sobre as tendências de redução ou ampliação dos efetivos militares. 


\section{RAZÕES DO ENCOLHIMENTO}

O senso comum tende a associar a redução dos efetivos militares às crises econômicas - que induzem cortes de despesas públicas - ou ao abrandamento de tensões internacionais, nodatamente em virtude do fim da Guerra Fria. Outra noção simplória é a associação direta entre o tamanho dos efetivos e a capacidade militar. Mesmo oficiais graduados sem maior intimidade com a história das estratégias, das relações internacionais e mesmo das organizações militares absorvem e reproduzem estas noções do senso comum.

Na verdade, a redução do número de militares em relação aos agregados populacionais vem de longa data, e é fomentada, sobretudo, pela inovação tecnológica. É o aperfeiçoamento e a ampliação da capacidade destrutiva das armas que força, em primeira instância, a reorganização, o treinamento e o encolhimento dos exércitos sem que isso represente perda de suas possibilidades operacionais. Quanto maiores, mais poderosos e eficazes os arsenais, menores os efetivos propriamente militares e mais ampla a participação considerada "civil" nos negócios da guerra.

Antes da arma de fogo, a capacidade militar dos Estados era medida basicamente pela quantidade, habilidade e disposição de luta dos combatentes mobilizados. No mundo tribal, todos os homens são guerreiros e, na antiguidade, a guerra envolvia todos os cidadãos; a possibilidade de confronto sangrento pautava o cotidiano das comunidades. Mesmo em sociedades de estruturação mais complexa, como na Grécia antiga, não havia distinção nítida entre o civil e o militar. Ao longo do domínio imperial de Roma e durante o medievo, quando prevaleciam a arma branca e as fortificações, a condição de um nobre era ditada por sua força própria, por seu talento nas intrigas e no estabelecimento de alianças. Sem integrar necessariamente corporações, o nobre exercia atividade militar e sua projeção política era diretamente relacionada com o tamanho de seu efetivo, o que pressupunha o domínio sobre terras férteis capazes de garantir a sobrevivência dos que lhe deviam obediência.

O desenvolvimento tecnológico alterou paulatinamente a tradicional proporção entre a força militar e os contingentes mobilizados para as refregas. Com a disseminação e o aperfeiçoamento da arma de fogo, o aprimoramento das embarcações e o surgimento de variados equipamentos de combate, a capacidade militar passou a derivar da qualidade técnica e da quantidade do material de guerra à disposição dos beligerantes. Passo a passo, o adestramento do efetivo e o talento dos comandantes na articulação dos variados e complexos meios ao seu dispor passou a ser decisivo. 
Obviamente, ao longo do tempo, a perspicácia e o talento dos comandantes militares tiveram de ser reforçados pelo preparo técnico especializado, pela galvanização e pelo treinamento dos combatentes e, enfim, por novos recursos de mobilização da sociedade como um todo. No início do século XVI, ao considerar que o Príncipe necessitava de "boas armas e boas leis", Maquiavel já se referia diretamente tanto aos aspectos técnicos quanto aos políticos da força militar de um Estado. A superioridade técnica e a mobilização de homens armados foram exemplares nos primeiros séculos da modernidade, quando algumas centenas de europeus, portando armas de fogo, lograram exterminar rapidamente grandes civilizações no "Novo Continente". Maias, astecas, incas e incontáveis povos pré-colombianos não resistiram às armas de fogo.

Nos últimos dois séculos, com a evolução da indústria, a relação entre os recursos técnicos e o poderio militar foi exponencialmente acentuada. Um punhado de homens equipados com canhões de maior alcance e precisão, com fuzis de repetição e metralhadoras automáticas no final do século XIX detinha capacidade destrutiva muitas vezes superior a dezenas de milhares de soldados cem anos antes. A mobilização de grandes massas de combatentes por Napoleão foi cedendo lugar aos exércitos profissionais, ajuntamentos de homens treinados e disciplinados, submetidos a normas corporativas e capazes de usar de forma adequada armas sofisticadas, que lhes exigiam capacidade de planejamento, preparo técnico específico e adestramento. A redução relativa e paulatina do tamanho dos exércitos seria também ditada pelas dificuldades logísticas e pelos problemas disciplinares: quanto maiores e mais aparelhados os exércitos, mais complexos e dispendiosos os deslocamentos, manutenção e abastecimento; menores chances de treinamento especializado e mais riscos para a manutenção da hierarquia e da disciplina.

O modelo da "grande armée" de Napoleão, um exército imperialista que mesclava homens das mais variadas regiões europeias, foi dando lugar aos exércitos de cidadãos com laços afetivos com comunidades identificadas - que se tornavam conhecidas como "nacionais" - comandados por oficiais de carreira preparados em escolas especializadas. Nesta matéria, os prussianos, ao derrotar os franceses em 1870, pavimentaram com sucesso o caminho a ser seguido por todos os Estados europeus e americanos. A tropa moderna passou a ser formada por cidadãos obrigados a pagar o "imposto de sangue", ou seja, a prestar o serviço militar obrigatório. A legitimidade da força derivaria da mobilização do sentimento nacional; a entidade a ser defendida não era exatamente o Estado, 
mas uma sociedade abstrata, coesa, pressupostamente unida por laços de origem imemorial designada como "pátria" ou "nação". Esta fórmula, rapidamente consagrada no Ocidente, ao tempo em que reduzia os gastos públicos com pessoal, deixava grandes contingentes de reservistas à disposição dos comandantes. A tropa buscava encarnar o sentimento social mais elevado de amor à comunidade; jurava solenemente matar ou morrer em sua defesa.

Este recurso de legitimação da força atingiu o seu auge na Segunda Guerra Mundial, quando foram mobilizados mais de cem milhões de combatentes e um incontável número de civis em trabalhos conexos. A quantidade real de vítimas desta conflagração talvez nunca seja efetivamente conhecida, mas o fato é que toda a humanidade foi afetada pela carnificina. Desde então, a velha tendência de encolhimento dos exércitos ganhou aceleração. O volume do efetivo combatente tornou-se cada vez menos relevante em relação ao poder de fogo dos instrumentos nas mãos dos militares.

Os Estados Unidos passaram a ditar as cartas na política internacional ao tempo em que encolhiam suas tropas; contando com a arma nuclear, entre 1945 e 1947, reduziram o contingente mobilizado de 12 milhões para pouco mais de 1,5 milhão. No final da guerra, os Estados Unidos dispunham de 91 divisões de combate do Exército e seis divisões de fuzileiros navais; em 1947, apenas dez divisões de combate do Exército e duas de fuzileiros foram mantidas. Houve reduções drásticas na Marinha, cuja frota passou de 8.165 para 1.003 navios; a Força Aérea, que tinha 218 grupos de aviação, passou a ter apenas 38 (CONDIT, 1979).

Crises econômicas conjunturais ou conflitos armados certamente afetam as dimensões dos efetivos militares, mas não desfazem a propensão geral de redução contínua dos contingentes. No concernente à redução de gastos, as estatísticas disponíveis, mesmo sujeitas a interpretações, desmentem a ideia de que o encolhimento dos efetivos decorra primordialmente da contenção de gastos.

Os países mais desenvolvidos são os que mais ampliaram a relação entre a despesa militar e a redução de pessoal. Sob o discurso da necessidade de contenção de gastos com efetivos militares em favor do equilíbrio orçamentário, as forças armadas das maiores potências militares aumentaram substancialmente seus investimentos na última década.

A tendência de queda nos gastos após a dissolução da URSS chegou ao seu menor patamar em 1998, quando a soma total das despesas militares no mundo atingiu US\$ 833 bilhões. Depois disso, o crescimento foi contínuo, como se pode verificar no gráfico a seguir (GRÁFICO 5). 


\section{Gráfico 5: Gastos militares no mundo (em US\$̦ bilhões)}

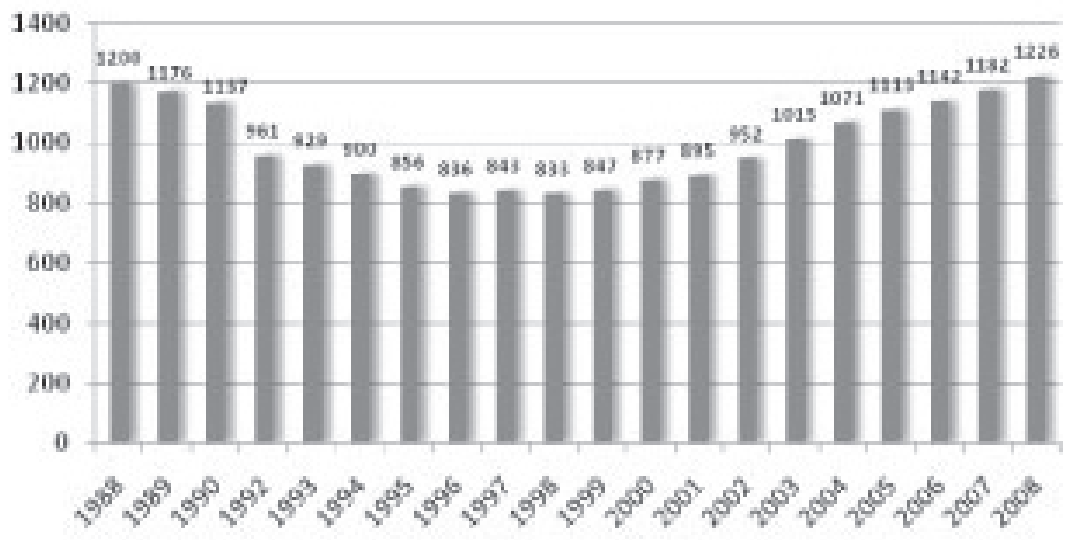

Fonte: Gráfico elaborado a partir dos dados obtidos no SIPRI Yearbook 2009, appendix 5A, tabela 5A.1 e tabela 5A.3, e no SIPRI Military Expenditure Database. ${ }^{8}$

Segundo O SIPRI, os gastos militares globais cresceram cerca de 45\% em termos reais entre 1998 e 2008. A partir de 2001, o crescimento variou entre 2,2\% e 5,3\% por ano, tendência puxada pelos Estados Unidos, que em 2010 foram responsáveis por 45\% dos gastos militares mundiais e 63\% do aumento dos gastos globais pós-2001. Ainda de acordo com o SIPRI, desde 2001, os gastos militares dos EUA cresceram 59\% em termos reais, sobretudo em decorrência das operações militares no Afeganistão e no Iraque.

$\mathrm{Na}$ tentativa de controlar o déficit das finanças públicas, a redução de efetivos militares sempre aparece em destaque. Os dados fornecidos pelo Departamento de Defesa dos EUA mostram que os dispêndios com salários, planos de saúde, assistência médica, assistencia social e aposentadorias chegaram, em 2009, a US\$ 154 bilhões, o que representa 23\% dos gastos militares fixos por ano nos EUA. Mas este dado pode induzir a erros, uma vez que a manutenção de tropas em operações militares ou em treinamento custou cerca de US\$ 283 bilhões, ou seja, 41\% do total despendido pelos EUA.

8 O total mundial e os totais para as regiões nessa tabela são estimativas, com base nos dados constantes (2005) na base de dados do SIPRI denominada US\$ Military Expenditure Database. Não se trata, portanto, de dados históricos. Quando os dados das despesas militares de um país estão ausentes por alguns anos, as estimativas são feitas, na maioria das vezes, seguindo o pressuposto de que a taxa de variação da despesa militar do país é a mesma que para a regiẫo a que pertence. Quando não há estimativas a serem feitas, os países são excluídos da pesquisa. Nesse caso, os países excluídos são Cuba, Guiné Equatorial, Guiana, Haiti, Mianmar (Birmânia), Coreia do Norte, Catar, Somália, Trinidad e Tobago e Vietnã (Editado pelo SIPRI; tradução nossa). 
O gráfico a seguir (GRÁFICO 6) oferece uma visualização das despesas militares estadunidenses. É óbvio que uma comparação com qualquer outro país não passa de exercício intelectual de validade duvidosa, porquanto, até o presente, no mundo globalizado, apenas os Estados Unidos tentaram agir como polícia planetária. Não obstante, é válido para observar a estrutura de despesas de um Estado cujos movimentos, bem ou mal, inspiram, ou mesmo condicionam, todos os países que buscam modernizar sua força armada.

\section{Gráfico 6: Gastos militares nos EUA em 2009}

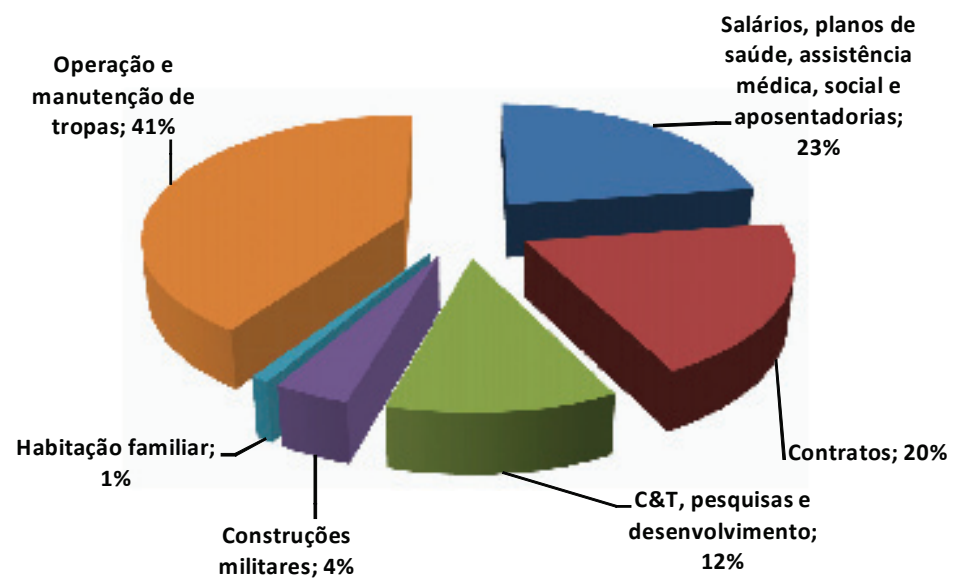

Fonte: Gráfico elaborado a partir de dados obtidos na tabela 3.2 - Outlays by Function and ubfunction: $1962-2014$. Disponível em: www.whitehouse.gov/omb/budget/Historicals/. United States Department of Defense Annual Report- Fiscal year 2010. Acesso em: em $22 / 10 / 2011$.

A maioria dos países também ampliou seus orçamentos militares a partir de 2001. Os motivos variaram de região para região e de país para país. Do total de 151 países para os quais havia dados disponíveis no período de 2001 a 2007, o número daqueles que aumentaram seus dispêndios subiu de 98 para 106 entre 2001 e 2006, e passou para 117, em 2007. Seria insensato comparar as preocupações relativas à Defesa do Oriente Médio com as da América do Sul, por exemplo. A Estratégia Nacional de Defesa adotada em 2008 pelo Brasil reflete preocupações de médio e longo prazos, bem distantes das que atormentam os países árabes, notadamente os que dispondo de grandes reservas de petróleo viram de perto a destruição do Iraque e convivem com a belicosidade israelense.

A pretensão de garantir seus espaços nos novos arranjos da divisão internacional de poder é responsável pela evolução das despesas 
militares nos países do BRIC (Brasil, Rússia, Índia e China). Esta propensão também ocorre na Europa Central e Oriental, principalmente pelos países que aderiram ou pretendem aderir à OTAN, e em alguns países da África Central, onde a expectativa é de continuidade das disputas sangrentas intermináveis. A luta pelo controle dos recursos naturais da África faz com que este continente seja tomado como provável cenário de banhos de sangue nas próximas décadas. A costa ocidental africana é uma grande plataforma para o domínio do Atlântico Sul, onde atualmente se desenvolvem promissoras prospecções de petróleo e onde barcos de variadas origens sentem-se à vontade para a pesca predatória.

De acordo com a tabela a seguir (TABELA 1), entre os 15 maiores orçamentos militares do mundo, apenas Alemanha e Japão tiveram redução nos gastos entre 1999 e 2008. A Arábia Saudita e a Coreia do Sul tiveram aumento considerável de seus contingentes. 
Tabela 1: Os 15 países com maiores gastos militares em 2010

Valores em US\$, com preços e taxas de câmbio correntes

\begin{tabular}{|c|c|c|c|c|c|c|}
\hline RANKING & País & $\begin{array}{l}\text { GASTOS } \\
\text { (US\$) } \\
\text { BILHÕES) }\end{array}$ & $\begin{array}{l}\text { VARIAÇÃO } \\
2000- \\
2009 \\
\text { (\%) }\end{array}$ & $\begin{array}{l}\text { GASTO } \\
\text { PER } \\
\text { CAPITA } \\
\text { (US\$) }\end{array}$ & $\begin{array}{l}\text { TOTAL } \\
\text { DO PIB } \\
\text { (\%) }\end{array}$ & $\begin{array}{l}\text { TOTAL } \\
\text { MUNDIAL } \\
\text { (\%) }\end{array}$ \\
\hline 1 & EUA & 661 & 75,8 & 2100 & 4,3 & 43 \\
\hline 2 & China & [100] & 217 & {$[74,6]$} & {$[2,0]$} & {$[6,6]$} \\
\hline 3 & França & 63,9 & 7,4 & 1026 & 2,3 & 4,2 \\
\hline 4 & $\begin{array}{l}\text { Reino } \\
\text { Unido }\end{array}$ & 58,3 & 28,1 & 946 & 2,5 & 3,8 \\
\hline 5 & Rússia & {$[53,3]$} & 105 & [378] & {$[3,5]$} & {$[3,5]$} \\
\hline \multicolumn{2}{|c|}{$\begin{array}{l}\text { Subtotal } \\
5 \text { maiores }\end{array}$} & 937 & & & & 61 \\
\hline 6 & Japão & 51 & $-1,3$ & 401 & 0,9 & 3,3 \\
\hline 7 & Alemanha & 45,6 & $-6,7$ & 555 & 1,3 & 3,0 \\
\hline 8 & $\begin{array}{l}\text { Arábia } \\
\text { Saudita } * *\end{array}$ & 41,2 & 66,9 & 1603 & 8,2 & 2,7 \\
\hline 9 & Índia & 36,3 & 67,3 & 30,4 & 2,6 & 2,4 \\
\hline 10 & Itália & 35,8 & $-13,33$ & 598 & 1,7 & 2,3 \\
\hline \multicolumn{2}{|c|}{$\begin{array}{l}\text { Subtotal } \\
10 \text { maiores }\end{array}$} & 1147 & & & & 75 \\
\hline 11 & Brasil & 26,1 & 38,7 & 135 & 1,5 & 1,7 \\
\hline 12 & $\begin{array}{l}\text { Coreia do } \\
\text { Sul }\end{array}$ & 24,1 & 48,2 & 499 & 2,8 & 1,6 \\
\hline 13 & Canadá & 19,2 & 48,8 & 568 & 1,3 & 1,3 \\
\hline 14 & Austrália & 19,0 & 50,2 & 892 & 1,8 & 1,2 \\
\hline 15 & Espanha & 18,3 & 34,4 & 408 & 1,2 & 1,2 \\
\hline \multicolumn{2}{|c|}{$\begin{array}{l}\text { Subtotal } 15 \\
\text { maiores }\end{array}$} & 1254 & & & & 82 \\
\hline \multicolumn{2}{|l|}{ Mundo } & 1531 & 49,2 & 224 & 2,7 & 100 \\
\hline
\end{tabular}

Fonte: Tabela elaborada com dados do SIPRI <http://www.sipri.org/databases/milex/> e United Nations Population Fund (UNFPA), State of World Population 2009: Facing a Changing World-Women, Climate and Population (UNFPA: New York, 2009, p. 91. Acesso em: 19/8/2011.

[ ] = Estimativas; PIB = Produto Interno Bruto.

* Os valores para as despesas militares nacionais em relação ao percentual do PIB são de 2008.

** Os valores para a Arábia Saudita incluem gastos para manutenção da ordem pública e segurança, podendo estar sobre-estimados. 
Um determinado grupo de países aumentou seus dispêndios ao tempo em que reduziu drasticamente seus contingentes. Segundo o Royal United Services Institute for Defence and Security Studies (RUSI), as despesas com pessoal civil e militar ficaram por volta de 36\% do custo total da defesa na Inglaterra em 2008. ${ }^{9}$ Mesmo com a diminuição dos contingentes, os gastos totais aumentaram nos últimos anos; na atualidade, as forças britânicas são levadas a adotar severos cortes. Autoridades britânicas avaliam a possibilidade de reduzir o tamanho do Exército, hoje com cerca de 98 mil homens e mulheres bem treinados, para cerca de 80 mil, em 2012. A justificatica, como bem expressou um oficial britânico hoje na reserva, é que o corte na "força de trabalho" seria mais factível dado que a maior parte dos recursos foi gasta em equipamentos, sendo impossível recuperá-la. ${ }^{10}$ O Ministério da Defesa britânico discute hoje "linhas de trabalho" que permitam preservar sua capacidade operacional mesmo com efetivos reduzidos.

A estrutura de gastos militares das grandes potências e de alguns países em desenvolvimento difere das de nações que, enfrentando instabilidade política e econômica, são compelidas ao aumento de despesas militares. Sem acesso a equipamentos mais sofisticados e sem chances de desenvolver domínio tecnológico próprio, tais países acumulam despesas com aquisições de armas e com a ampliação de seus contingentes.

A forma como uma força armada desenvolve ou absorve tecnologias condiciona sua estrutura organizacional. Como assinalou Betts (1997), diferentes tipos de operações implicam diferentes graus de importância para os vários serviços armados. Países situados em área de conflitos de baixa intensidade ou que desenvolvem operações de paz, como o Brasil, tendem a aplicar mais em unidades de combate do Exército e de fuzileiros navais e desenvolvem programas cujos resultados não virão no curto prazo; já aqueles sob grande tensão com seus vizinhos buscam obter o mais rapidamente possível armamento de alto poder ofensivo, adquirindo sofisticados sistemas de armas de longo alcance. Neste caso, valorizam mais a força aérea do que as tropas de combate terrestre e têm mais dificuldades para sustentar programas de longo prazo.

9 CHALMERS, Malcolm. Capability Cost Trends: Implications for the Defence Review. In: Future defense Review. Londres: Royal United Services Institute, janeiro de 2010.

10 FOX, Robert. British Army could shrink to its smallest since the Boer War. London Evening Standard. Londres: 7 de Junho de 2010. Disponível em: http://www.thisislondon.co.uk/standard/article-23842126-british-army-could-shrink-to-its-smallest-size-since-the-boer-war.do. Acesso em: 9/9/2010. 
Já o Paquistão e a Arábia Saudita, que não se destacam no desenvolvimento tecnológico de armas de combate, mas experimentam grandes tensões, tendem a ampliar assustadoramente suas forças militares, em especial seus exércitos, contrariando a tendência geral de redução dos efetivos. O grupo de países que ampliam suas tropas é muito heterogêneo, porém, no geral, não logram reforçar suas capacidades dissuasórias; de sobra, aumentam seus problemas econômicos.

Poucas instituições no mundo têm tanta experiência na redução de efetivos como as estadunidenses. Na ausência da superpotência que lhe arranhava a hegemonia, o Pentágono admitiu a necessidade de novos paradigmas para a defesa nacional e buscou reestruturar suas forças. Neste sentido, deslocou recursos para o financiamento de modernos sistemas de armas que, em muitos casos, substituiriam bases militares consideradas pouco eficientes ou obsoletas. Sistemas de mísseis terraar, ar-ar e mísseis lançados por submarinos guiados por complexos sistemas de satélites e potentes computadores tornaram desenecessária a presença física de pessoal em áreas consideradas "problemáticas". Um simples apertar de botão em local bem distanciado da zona de conflito pode resultar em efeitos destrutivos superiores aos de numerosos e dispendiosos batalhões. Soldados estadunidenses ficam cada vez mais parecidos com usuários de videogames: no conforto de suas poltronas, bem protegidos e alimentados, eliminam seres humanos sem ouvirem seus gritos de dor; o desespero das comunidades agredidas e sem chances de revide não lhes atinge. Nada mais adequado que a expressão "cirúrgica" para definir este novo tipo de combatente: aos cirurgiões não é dado o direito de abalos emocionais. Parte dos recursos destinados aos efetivos estadunidenses foi redirecionada para cobrir déficits orçamentários, mas os gastos com inovação tecnológica persistiram (GARGAN, 1999).

Ainda é cedo para prever as múltiplas consequências morais, éticas, políticas e militares, propriamente ditas, da substituição de combatentes de carne e osso por engenhos de grande eficácia destrutiva movidos a distância. Mas está cada vez mais evidente que a assimetria de meios militares, que assombram estrategistas em todos os continentes, não favorece indiscutivelmente a única superpotência de nossos dias. Nas duas guerras nas quais os mais sofisticados e caros engenhos foram usados contra forças infinitamente inferiores, no Afeganistão e no Iraque, os pretensos vencedores não lograram impor sua vontade e não retornaram ao lar cobertos de glórias; sobram, à sociedade estadunidense, as despesas e transtornos com ex-combatentes. Abundam na internet depoimentos 
de soldados veteranos repudiando as atitudes das corporações e do governo aos quais serviram.

Segundo dados do SIPRI, boa parte dos gastos militares se volta para o setor de serviços entregues a empresas privadas. A contratação de mercenários também é decisiva para o enxugamento das forças armadas. Revisão e manutenção de equipamentos, sistemas logísticos e de informação, gerenciamento de instalações, etc. são entregues a firmas especializadas. ${ }^{11}$ Algumas empresas contratadas são tradicionais fornecedoras de equipamentos de alta tecnologia como a Boeing, Lockheed Martin, BAE Systems, Raytheon, Rolls-Royce e HewlettPackard, contudo surgem constantemente novas firmas oferecendo serviços de interesse militar. O complexo industrial-militar se sofistica e amplia a cada ano seus lucros com a guerra, o que resulta no fortalecimento das relações entre os militares e empresas privadas voltadas para a inovação. ${ }^{12}$

Não é difícil constatar a perda de envolvimento das sociedades ricas com as decisões de seus Estados na esfera militar. A natureza das guerras desencadeadas pelas grandes potências empalidece o mais poderoso mobilizador dos cidadãos: o discurso de defesa da pátria. O apelo patriótico perde sua sedução quando fica claro que o objetivo da guerra é o mero domínio de recursos naturais. As famílias, mesmo as de parcelas mais pobres de ricas sociedades ocidentais, sempre as mais generosas na oferta de homens para as fileiras, tomam cada vez mais o serviço militar voluntário como uma oportunidade para os que não têm chances de melhor emprego. As mortes de soldados ocidentais no Afeganistão e no Iraque alimentam o repúdio social às guerras desencadeadas pelas grandes potências. Daí o apelo crescente aos serviços de mercenários e à terceirização de numerosas atividades que tradicionalmente estiveram a cargo das corporações militares.

11 Military expenditure: SIPRI Yearbook 2008: Armaments, Disarmament and International Security. Oxford: Oxford University Press, 2008, Appendix 5A.

12 Para uma discussão mais detalhada sobre o setor de serviços militares consulte também Perlo-Freeman, S. e Sköns, E. The Private Militar Services Industry, SIPRI Research Paper 001, 2008. 


\section{REFERÊNCIAS}

AGIESTA, J.; COHEN, J. Public opinion in U.S. turns against afghan war. Washington Post. Aug. 20, 2009.

BETTS, R. K. Power, Prospects, and Priorities. National War College Review, V. 50, n.1, p. 11- 22, 1997.

CHALMERS, M. Capability Cost Trends: Implications for the Defence Review. In: Future defense Review. Londres: Royal United Services Institute. Jan. 2010.

COHEN, W.; SHALIKASHVILI , J.; LEHRER, J. Department of Defense Newsmakers. Transcript. Online NewsHour. Public Broadcasting Service. May 19, 1997. Disponível em http://www.pbs.org/newshour/bb/military/may97/qdr_519.html. Acesso em: 16/8/2010.

CONDIT, Kenneth W. The history of the Joint Chiefs of Staff: the Joint Chiefs of Staff and National Policy. V. II, 1947-1949. Wilmington: Glazier, 1979.

FOX, R. British army could shrink to its smallest since the Boer War. London Evening Standard. Londres: 7 Jun. 2010. Disponível em: http://www. thisislondon.co.uk/standard/article-23842126-british-army-could-shrink-to-itssmallest-size-since-the-boer-war.do. Acesso em: 9/9/2010.

GARGAN. J. J. To defend a nation: an overview of downsizing and the U.S. military. In: M@n@gement, v. 2, n. 3, 1999, p. 221-232. Disponível em: www. management-aims.com/PapersMgmt/23Gargan.pdf. Acesso em: 28/7/2010.

IISS (International Institute for Strategic Studies). The military balance 2001 2002. Oxford: Oxford University Press, 2010. 2010. The military balance 2009-2010. Oxford: Oxford University Press,

PERLO-FREEMAN, S.; SKÖNS, E. The private militar services industry. SIPRI Research Paper 001, 2008. Disponível em: www.sipri.org. Acesso em: 6/6/2010.

SIPRI Yearbook 2008: Armaments, disarmament and international security. Oxford: Oxford University Press, 2008. 